\title{
AS FIGURAS MATERNAS EM SÃO BERNARDO, DE GRACILIANO RAMOS
}

\author{
Angela Maria Rubel Fanini ${ }^{1}$ \\ Joanelise Brandão ${ }^{2}$
}

\section{Resumo}

Esse trabalho se dedicou a identificar as abordagens da maternidade no romance São Bernardo, escrito pelo autor alagoano- Graciliano Ramos- e publicado, em 1934. A ficção revelou-se como uma interessante fonte de pesquisa literária, também sociológico-histórica e cultural, ao retratar de forma crítica as relações humanas, sociais e familiares de uma elite agrária e burguesa no sertão nordestino brasileiro durante a República Velha. Privilegiamos a análise dos personagens femininos, ligados ao núcleo familiar do protagonista, Paulo Honório, mas também ganharam foco personagens masculinos da convivência social do protagonista. Tivemos como intuito identificar as funções maternais e o exercício da maternidade por personagens de ambos os sexos. Pudemos averiguar que a atuação materna não é inata, mas construída nas relações sociais concretas. Investigamos também as relações entre traços estéticos-formais na narrativa e o contexto do Brasil nos 30 anos iniciais do século XX.

Palavras-chave: Cultura. Sociedade. Maternidade. Narrativa brasileira. Graciliano Ramos.

\begin{abstract}
This essay is devoted to identify the motherhood approaches in the novel $S$. Bernardo, written by the author from Alagoas- Graciliano Ramos- and published in 1934. This fiction has been revealed as an interesting source for literary research and for sociological and cultural-historical research while portraying critically the human, social and family relations of an agricultural and bourgeois elite in northeastern Brazil backland during the Old Republic. We mainly focus the analysis, specially, on female characters connected to the nuclear family of the protagonist, Paulo Honorio, but male characters, inside the protagonist social life, were also studied. We had as an intention to identify the maternal functions, the motherhood exercise between both sexes characters. Our approach proves that motherhood is not innate but culturally constructed. Besides that, the formal-aesthetic features in the narrative and their connections to the Brazilian context in the first 30 years of the $20^{\text {th }}$ century were investigated.
\end{abstract}

Keywords: Culture. Society. Maternity. Brazilian Narrative. Graciliano Ramos.

\section{Objeto da análise e marco teórico}

Na narrativa São Bernardo encontramos uma gama de elementos que facilmente podem ser associados ao seu contexto de elaboração e representam aspectos da realidade social externa à obra. Buscamos encontrar na ficção associações entre os traços estéticonarrativos-composicionais ${ }^{1}$ sobre a maternidade que refletiriam características culturais e

\footnotetext{
${ }^{1}$ Doutora em Teoria da Literatura pela Universidade Federal de Santa Catarina (2003).

Professora de Ensino Superior da Universidade Tecnológica Federal do Paraná - Campus Curitiba, Brasil. E-mail rubel@utfpr.edu.br

${ }^{2}$ Especialista em MKT. Acadêmica de Letras Português/Inglês UTFPR-Curitiba. E-mail jobrandao@gmail.com
} 
históricas do sertão de um Brasil oligárquico, agrário e ainda em transição entre a República Velha e a Nova, contexto em que os jogos de poder e de interesses envolviam as relações sociais. Nesse sentido, privilegiamos primeiramente nossa análise nos personagens femininos, com intuito de identificar as abordagens da maternidade e o exercício da maternidade, inclusive investigando se a literatura representa o padrão social, a cultura patriarcal e os comportamentos vigentes naquele período. Entretanto essa análise não foi majoritária haja vista que também investigamos personagens masculinos no tocante ao tema em tela visto que a narrativa assim o exigia. Essas relações que aqui tentamos estabelecer - obra $e$ sociedade foram pensadas à luz de conceitos propostos por Candido (1985) e Goldman (1976), além da filosofia histórica de Badinter (1985).

Para Candido (1985), uma análise crítico-literária deve visualizar a obra como uma fusão de texto e contexto, assumindo-se tanto os elementos sociológico-históricos quanto os estruturais (formais), ocorrendo em conjunto e jamais independentemente. Entretanto não confirma a homologia ipsis literis entre ficção e realidade. Assevera que não podemos nos esquecer de levar em consideração que entre o real, fora da obra literária, e sua migração para o interior da obra, há inúmeras mediações. O escritor apresenta uma certa visão de mundo (otimista, satírica, pessimista, conservadora, revolucionária) e plasma a realidade a partir dessa mediação. Essa articulação vai ser responsável pela economia formal da obra visto que o escritor arregimenta certos componentes formais para construir sua visão de mundo que não deixa de se atrelar ao contexto imediato, mas o retrata e o transcende de uma maneira que lhe é peculiar.O crítico destaca: “Sabemos, ainda, que o externo (no caso, o social) importa, não como causa. Nem como significado, mas como elemento que desempenha um certo papel na constituição da estrutura, tornando-se, portanto, interno.”( CANDIDO, p. 4, 1985).

Candido nega a simples equivalência entre obra e meio social ${ }^{2}$ e expõe a intrincada ligação entre ambos. Apresenta com cautela essa articulação, expondo com clareza a questão da "redução estrutural” dos dados externos que se transformam em internos na economia narrativa. Seguindo essa linha, percebemos que o romance elabora um recorte do social e formaliza-o na narrativa, possibilitando-nos enxergar o histórico no ficcional.

Para Goldman também há uma relação bastante orgânica entre a obra e o meio, pois para esse autor o romance desponta no século XIX, vindo para representar a sociedade burguesa e suas contradições internas, suas lutas, seus anseios e seus projetos. O herói para esse crítico, recuperando todo um cabedal lukacsiano, é aquele que busca valores autênticos em um mundo degradado pelo valor de mercado. O protagonista de romances e também os 
personagens secundários, muitas vezes, buscam sair do círculo da mercantilização, mas a ele sucumbem, pois estão inseridos em uma sociedade liberal-burguesa em ascensão e fortalecimento. Nosso herói e heroína - Paulo Honório e Madalena - em várias instâncias narrativas, buscam essa fuga, mas ela é infrutífera. O destino trágico de ambos atesta essa luta por valores autênticos em um mundo venal em que o valor de mercado impera nas relações sociais e afetivas. O romance ora analisado se insere em uma linha realista da década de 30 do século XX e representa, em parte, a realidade histórico-social daquele momento indo ao encontro das considerações de Goldman (1976). O cenário nacional da época da escritura se acha em franca aderência às ideias liberais e ao valor de mercado. Paulo Honório recria esse cenário, vivenciando em muitas situações narrativas o universo do ter, apoderando-se de todos e tudo à sua volta por intermédio de valores de mercado. Entretanto essa relação venal do protagonista é contraditória visto que ele busca valores autênticos e os vivencia em parte, lembrando o herói de Goldman.

Para Badinter (1985), os papéis feminino e masculino são majoritariamente construídos social e culturalmente, afastando-se de uma visão de perspectiva inatista e biológica em que esses são dados como definitivos e conclusivos. O exercício da maternidade pode ser executado a partir de práticas e regras culturais aprendidas, requisitadas e/ou enaltecidas por ambos os gêneros. Ao longo da história, a antropóloga comprova haver uma conexão cultural entre maternidade e seu exercício, distanciando-se de uma visão estereotipada. Os papéis maternos não são dados de modo inato, mas aprendidos ou socialmente requeridos. O cuidado dos infantes, a cada cultura e momento histórico, pode variar, inclusive obliterando o papel feminino. O amor materno não é inerente à condição humana e não é totalmente instintivo, mas exercido em condições materiais e culturais reais, podendo ser diferente para cada cultura e momento histórico. Baseados nessa autora, pudemos ler o exercício da maternidade em São Bernardo a partir de um mirante cultural e das construções ficcionais do texto. Aí encontramos o avesso da estereotipia, pois como veremos na sequência, a maternidade é exercida pelos personagens menos esperados do ponto de vista biológico e culturalmente aceitos.

Graciliano, em São Bernardo, mostra as condições do processo de modernização capitalista que se inicia no Brasil na década de 1930 e a mentalidade patriarcal na figura de Paulo Honório, enfatizando as conseqüências sociais deste processo, apresentando inclusive uma crítica a essa modernização. Essa se dá sob o império do mercado e da racionalidade instrumental e submete os sujeitos do cenário. Como já referido, o protagonista atesta essa 
reorientação capitalista e pragmática no campo, assujeitando seus empregados e familiares a essa ótica. Além disso, o patriarcalismo é outro componente nesse cenário que auxilia as tomadas de posição do protagonista que a todos submete com seu jugo. As figuras femininas tais como Madalena, D. Glória e Negra Margarida são diretamente atingidas por esse contexto visto que nele se inserem uma vez que são dependentes materialmente de Paulo Honório. Selecionamos apenas situações narrativas em que esse contexto patriarcal e pragmático gera conflitos e desdobramentos nos relacionamentos familiares e trabalhistas em torno da personagem Paulo Honório. O exercício da maternidade foi privilegiado para a análise, buscando-se perceber como e por quem é operacionalizado, buscando-se investigar como o escritor formaliza o contexto da maternidade em um universo de poder masculino, recriando ficcionalmente a realidade, por meio da estética narrativa, reconstruindo, até certo ponto, suas estruturas sociais e culturais.

Para Goldman (1976), o romance representa um gênero literário tipicamente burguês e que evoluiu, em termos estético-formais, paralelamente às mudanças sofridas pela estrutura da sociedade liberal. O romance, segundo Goldman, exibe, por meio de sua estética, homologia com a sociedade burguesa, caracterizada primordialmente por valores de troca e pelo individualismo, uma sociedade em que se enalteceram, nas relações inter-humanas, os valores de troca puramente quantitativos, havendo prejuízo dos valores qualitativos (valores de uso). Muitos analisam o romance em tela como modelar para a teoria de Goldman ao focalizar as contradições entre o universo do ser e do ter, sobretudo nas relações de Paulo Honório com os demais personagens. A personagem principal guia-se pelos valores de mercado, mas sucumbe visto que ao mercantilizar suas relações, corrompe-se em um universo degradado. Entretanto, ao encetar a narrativa que escreve (o romance é escrito em primeira pessoa pelo protagonista), questiona esse universo, revelando-se solitário e isolado. Demonstra com isso a vontade de se guiar por valores autênticos. Na narrativa, encontramos vários momentos em que aflora essa critica à contradição social. Em relação ao nosso foco de análise, o exercício da maternidade tanto na personagem Margarida quanto em Casimiro Lopes revela o poder dos laços afetivos podendo-se ler o romance a partir das lentes de Goldman. Essas personagens apresentam-se distantes da esfera da mercantilização, apresentando comportamentos afetivos e maternais, cuidando do outro sem esperar por recompensa material. Apenas as relações de fidelidade, lealdade e solidariedade regem sua ética no que concerne a certas situações narrativas. 


\section{A questão da maternidade}

São Bernardo conta a história de Paulo Honório, homem simples, despossuído materialmente, sem família biológica, porém ambicioso e de sua saga - para se tornar um grande fazendeiro, apoderando-se da fazenda São Bernardo, no sertão de Alagoas e sua busca para conseguir um herdeiro - através do casamento com Madalena. Esta é jovem, educada, instruída, prendada, inteligente e bonita. Também não é criada pelos pais biológicos, mas pela tia, D. Glória, que se esforçou para proporcionar a formação de professora à sobrinha. Ambas são pobres e, no casamento de Madalena com Paulo Honório, tem a oportunidade de melhorarem suas condições materiais de existência. Essas personagens são desprovidas de linhagens familiares. Os laços familiares apresentam outros nexos causais como se verá.

Em primeira pessoa, o narrador Paulo Honório participa de todos os detalhes descritos na obra, como se estivesse presente em todos os lugares e em todos os momentos (narrador onipresente). De menino pobre, criado por Negra Margarida, o herói-problemático e narrador divaga sobre si mesmo e sua vida passada, revelando seus conflitos psicológicos na busca da compreensão dos verdadeiros valores que deveriam reger as relações humanas; suas reflexões são problematizadas, principalmente, a respeito do seu desencontro com Madalena, da sua dificuldade de aceitação do mundo e de si mesmo, e da derrocada da propriedade de São Bernardo, tudo isso ao longo de uma vida marcada por ambição, poder e solidão.

Segundo Vianna, a narrativa estudada representa:

um romance masculino por excelência, escrito por homem, narrado por homem, este livro constrói um painel preciso da divisão social do mundo entre homens e mulheres, de acordo com o sistema patriarcal, mais resistente no Nordeste brasileiro, em face das condições culturais específicas da região. (VIANNA, 1999, p. 76).

Analisando o contexto histórico do Brasil em meados de $1930^{3}$, observamos que o elemento feminino, embora já engajado em inúmeras atividades laborais, ainda permanecia submetida aos ditames masculinos quer na esfera familiar quer no ambiente de trabalho. $\mathrm{O}$ contexto nacional tanto no meio urbano quanto no rural mantinha-se hegemonicamente dominado pelo elemento masculino haja vista, a título de exmplificação, que mulheres não podiam votar ou concorrer a cargos públicos no Executivo. Os postos de comando eram majoritariamente masculinos. No meio urbano há predominância de chefes, empresários e industriais do sexo masculino. Já no campo, prevalece o coronelismo do qual o protagonista é representante. Nesse cenário patriarcal, a sociedade brasileira permanecia sob uma ideologia 
vigente de maternidade em que a regra era de que as mulheres nasceriam, predominantemente, para serem mães, natural e instintivamente inclinadas à gestação, reflexo tardio do mesmo fato ocorrido anteriormente no final do século XVIII, na Europa. Percebemos que há uma dominante discursiva e cultural que visa construir a "naturalidade” de ser mãe. Badinter enfatiza essa discursividade para o contexto europeu o que também podemos perceber em solo nacional:

Veremos que se tornará necessário, no final do século XVIII, lançar mão de muitos argumentos para convocar a mãe para sua atividade “instintiva”. Será preciso apelar ao seu senso do dever, culpá-la e até ameaçá-la para reconduzí-la à sua função nutritícia e maternante, dita natural e espontânea. ( BADINTER, 1985, p. 144).

Entretanto, em São Bernardo, constatataram-se inúmeras exceções a essa regra considerada natural visto que o papel de mãe é muitas vezes exercido pela personagem mãe de criação, ama-de-leite e tia que operacionalizam o exercício materno diário. Nosso protagonista, Paulo Honório, não tendo família biológica a quem recorrer, remete à lembrança de sua mãe-de-criação, Margarida, ao descrever a sua única mémoria familiar.

Se tentasse contar-lhes a minha meninice, precisava mentir. Julgo que rolei por aí à tôa. Lembro-me [...] da velha Margarida, que vendia doces [...] A velha Margarida mora aqui em S. Bernardo, numa casinha limpa, e ninguém a incomoda. Custa-me dez mil-réis por semana, quantia suficiente para compensar o bocado que me deu. (RAMOS, 2008, p. 10).

Contudo, a personagem Margarida, longe da mercantilização que rege o comportamento das demais personagens, distancia-se dessa prática e envolve-se afetivamente para com Paulo Honório como se fosse sua verdadeira progenitora. Essa atitude lhe beneficia, pois quando Paulo Honório torna-se abastado fazendeiro, passa a ampará-la, lembrando-se de um dos únicos períodos em que sua vida foi guiada pela afetividade. Todavia, Margarida não é mãe biológica ou legal de Paulo Honório. O exercício da maternidade se dá em outro espaço social e cultural. Essa situação narrativa é bem significativa, pois é uma das poucas passagens em que o protagonista mostra sua afetividade e cuidado para com o outro, distante de uma relação de posse e mercantilizada. Paulo Honório demonstra desapego material ao se relacionar com Margarida e a partir dessa personagem se humaniza o que atesta a passagem: “Como estava com a vista curta, falou sem levantar a cabeça, repetindo os conselhos que me dava quando eu era menino. Uma fraqueza apertou-me o coração, aproximei-me, sentei-me na esteira, junto dela.” (RAMOS, p. 57) Aqui a reciprocidade de afetividade é um dos pontos fortes do romance visto que esse conta a história predominate da posse material. Isso, porém é 
netralizado pela relação afetiva das personagens referidas. A memória de mãe resgatada por Paulo Honório se apresenta na personagem Margarida.

Já Madalena, esposa de Paulo Honório, também fora criada por uma mãe não natural, sua tia, D. Glória, que ficou a cargo de sustentar a moça, participando da sua formação pessoal, contribuindo essencialmente para o êxito dos seus estudos no magistério, e, conseqüentemente, para a formação da "boa moça”, pré-destinada ao casamento.

\begin{abstract}
- Tomou conta de mim, sustentou-me e educou-me. [...] você não sabe o esforço que isso custou. [...] Morávamos em casa de jogador de espada, disse Madalena. Havia duas cadeiras. Se chegava visita, Dona Glória sentava-se num caixão de querosene. A saleta de jantar era o meu gabinete de estudo. A mesa tinha uma perna quebrada e encostava-se à parede. Trabalhei ali muitos anos. À noite baixava a luz do candeeiro, por economia. Dona Glória ia para a cozinha resmungar, chorar, lastimar-se. [...] Se eu adoecia, Dona Glória passava a noite sentada; quando não agüentava de sono, deitava-se no chão. (RAMOS, p. 87 - 88).
\end{abstract}

Entretanto, como veremos, Madalena, não reproduz a atividade materna, inspirando-se na tia, pois quando tem seu próprio filho com Paulo Honório, não exercita a maternidade. É alheia ao filho. Não ocorre a assimilação de uma conduta maternal, embora Madalena reconheça na tia a mãe biológica e afetiva que não tivera.

É senso comum que o desenvolvimento de uma criança exige afeto e cuidados pessoais realizados por outro ser humano que supram as necessidades básicas materiais e afetivas durante a infância.

A mãe suficientemente boa (não necessariamente a própria mãe do bebê) é aquela que efetua uma adaptação ativa às necessidades do bebê, uma adaptação que diminui gradativamente, segundo a crescente capacidade deste em aquilatar o fracasso da adaptação e em tolerar os resultados da frustração. [...] $\mathrm{Na}$ verdade, o êxito no cuidado infantil depende da devoção, e não de "instinto" ou conhecimento intelectual (WINNICOTT, 1953c [1951], p.25).

No exame do romance, elucida-se o paradoxo existente entre a maternidade inatabiológica e a contruída socialmente, pois Paulo Honório reforça a idéia da maternidade como um imperativo cultural, adequando-se a uma exigência social compatível com os padrões da época (exterior à obra). Para o protagonista, o papel de mãe deve ser exercido pelo elemento feminino e sai em busca de uma mulher com quem casar e ter um herdeiro. Deseja transmitir a propriedade que tem aos seus herdeiros e para isso deve concorrer uma mulher. Encontra então, Madalena, e lhe porpõe,de modo bem pragmático, casamento com um negócio.

Amanheci um dia pensando em casar. Foi uma idéia que me veio sem que nenhum rabo de saia a provocasse. Não me ocupo com amores, devem ter notado, e sempre me pareceu que mulher é um bicho esquisito, difícil de governar. A que eu conhecia era a Rosa do Marciano, muito ordinária. Havia conhecido também a Germana e 
outras dessa laia. Por elas eu julgava todas. Não me sentia, pois, inclinado para nenhuma: o que sentia era desejo de preparar um herdeiro para as terras de São Bernardo. (RAMOS, p.43).

No entanto, apesar de Madalena ser a única mãe biológica do romance, possuir comportamentos socialmente nobres e altruístas ao exercer seu ofício de professora e nas demais relações com os empregados da fazenda São Bernardo, auxiliando os desvalidos da sorte, ela foi incapaz de demonstrar qualquer tipo de afeto ou criar um vínculo com o próprio filho. Madalena exerce cuidados com os demais, como se fosse mãe deles, resguardando-os, alimentando-os e protegendo-os dos desmandos de Paulo Honório. Todavia, em relação ao seu filho natural, permanece alheia e distanciada do infante. A rejeição à criança é ponto significativo do romance, sendo constatada pelo protagonista:

\begin{abstract}
Afastava-me, lento, ia ver o pequeno, que engatinhava pelos quartos, às quedas, abandonado. Acocorava-me e examinava-o [...]. E o pequeno continuava a arrastarse, caindo, chorando, feio como os pecados. [...]. Gritava dia e noite, gritava como um condenado, e a ama vivia meio doida de sono. Às vezes ficava roxo de berrar, e receei que estivesse morrendo quando Padre Silvestre lhe molhou a cabeça na pia. Ninguém se interessava por ele. Dona Glória lia. Madalena andava pelos cantos, com as pálpebras vermelhas e suspirando [...] (RAMOS, p.105).
\end{abstract}

A personagem Madalena é mostrada pelas lentes do protagonista como ausente, despreocupada da maternidade e incapaz de demonstrar afeto e cuidar de seu filho. Essa perspectiva vai de encontro ao comportamento social da personagem em que se enfatiza um crescente cuidado para com o outro. A construção narrativa de Madalena a revela indiferente ao sofrimento e à solidão do filho, demonstrando claramente uma perspectiva contrária ao estereótipo feminino da mãe extremosa e cuidadora. O protagonista, embora tenha tentado delegar à Madalena o papel materno, também sofre por não se vincular afetivamente ao filho. Essa angústia de não poder se solidarizar com a criança é também ponto significativo na trama, pois vai de encontro ao universo brutal em que Paulo Honório vivera. Sente desejo de se ligar ao filho, mas vê-se incapaz de tal ato: “ Se ao menos a criança chorasse...Nem sequer tenho amizade a meu filho. Que miséria! (RAMOS, p.188).

Também a personagem D. Glória, tia de Madalena, permanece distante da criança e dela se afasta, não exercendo nenhuma atividade afetiva para com o infante. Parece que perdeu completamento o senso materno que tivera com a sobrinha.

O carinho, a afetividade e o amor para com a criança encontram-se em outro personagem, ironicamente em Casimiro Lopes - o capataz de Paulo Honório - descrito como “corajoso, laça, rasteja, tem faro de cão e fidelidade de cão” (RAMOS, p. 12). Ainda, na voz do narrador: "E o filho chorava, chorava continuamente. Casimiro Lopes era a única pessoa 
que lhe tinha amizade. Levava-o para o alpendre e lá se punha a papaguear com ele, dizendo histórias de onças, cantando para o embalar as cantigas do sertão” (RAMOS, p. 105). Vemos aqui um ponto inquietante do romance, pois a personagem menos apropriada a exercer o papel materno visto não apresentar nem laços legais nem biológicos ou atender papéis sociais estereotipados da figura materna, na realidade, é a única que se dedica à criança. As relações aqui se vinculam ao valor de uso e não mercantil, reforçando talvez as relações de lealdade que os agregados têm para com o proprietário das terras, distanciando-se do pragmatismo liberal-burguês de que trata Goldman como já referido. Em Casimiro, o protagonista insere a bondade, a autenticidade, distanciando-o do mundo venal e mercantilizado. Aí, o exercício da maternidade é uma prática inusitada do ponto de vista da realidade social, entretanto tem amparo na coerência narrativa visto que essa personagem é formalizada sob a perspectiva não mercantil. Casimiro é formalizado como capataz e jagunço, mas tendo uma alma bondosa, não se apresentando qualquer explicação racional ou objetiva para tal atitude. O exercício da bondade e do cuidado para com o outro é um dom inerente e natural à personagem, como uma devoção da qual trata Winnicott já referido. A seguir passagem do romance, apresentando Casimiro:

\footnotetext{
Boa alma, Casimiro Lopes. Nunca vi ninguém mais simples. Estou convencido de que não guarda lembrança do mal que pratica. Toda gente o julga uma fera. Exagero. A ferocidade aparece nele raramente. Não compreende nada, exprime-se mal e é crédulo como um selvagem. (RAMOS, p. 136).
}

Em São Bernardo o exercício da maternidade não segue a norma estabelecida pelo inatismo-biológico ou pelos papéis socialmente definidos para tal comportamento. O cuidado dos infantes se acha em mães não biológicas e em figuras de capangas, demonstrando outras regras construídas nas relações sociais concretas entre as personagens em que várias mediações concorrem. A fidelidade de Casimiro, em relação a Paulo Honório e seu filho, tem por base, em parte, o seu status de agregado da fazenda, revelando uma relação de lealdade e compromisso, distante de bases puramente materiais e racionais. Já a afetividade e o desvelo de Margarida com Paulo Honório tem por base apenas uma união de desafortunados pelo destino visto que tanto um como o outro não tem família biológica e se fortalecem a partir das dificuldades materiais e afetivas que enfrentam juntos. As personagens D. Glória e Madalena se fortalecem como família por laços consanguíneos, mas de segundo grau. Aqui também a dificuldade material e a necessidade de suporte afetivo as unem como grupo. Pode-se perceber que há mediações de vária ordem, distanciando-se da visão inatista ou culturalmente estereotipada como assevera Badinter: 
O amor, no reino humano não é simplesmente uma norma. Nele intervém inúmeros fatores que não a respeitam. Ao contrário do reino animal, imerso na natureza e submetido ao seu determinismo, o humano - no caso, a mulher- é um ser histórico, o único vivente dotado da faculdade de simbolizar, o que o põe acima da esfera propriamente animal”. (BADINTER, 1985, p.133).

Paulo Honório representa uma certa tipologia social, ou seja, recria em parte o mandonismo e a violência no campo dos grandes senhores de terra. A fazenda São Bernardo é ampliada às custas de crimes contra a propriedade de outrem como ocorre no cenário brasileiro em relação à questão fundiária. O protagonista narra uma situação em que se apossa de parte da fazenda vizinha por atos ilegais e criminosos, tomando as terras da família Mendonça. A morte do proprietário deixa as mulheres da fazenda indefesas em relação a outros fazendeiros. Paulo Honório, demonstrando sentimento de culpa e também afetividade para com as desamparadas em um universo hegemonicamente de poder masculino, decide ampará-las, revelando-se solidário e protetor. Essa atitude pode ser comparada a uma ação materna de proteção e cuidado, dentro dos limites patriarcais da personagem principal:

\begin{abstract}
Senti pena das Mendonça. Mandaria no dia seguinte dar uma limpa no algodão de Bom Sucesso, enfezado, coberto de mato. Muito por baixo as Mendonça. O pai era safado, mas que culpa tiveram as pobres? Resolvi abrir o olho para que vizinhos sem escrúpulos não se apoderassem do que era delas. Mulheres quase nunca se defendem. Pois se qualquer daqueles patifes tentasse prejudicá-las, estava embrulhado comigo.”(RAMOS, p. 45).
\end{abstract}

\title{
Considerações finais
}

Sobre os aspectos maternais encontrados nas personagens de São Bernardo cabe reforçar que a narrativa traz situações inusitadas, mas também se insere na realidade da época, retratando personagens que repetem, em parte, o comportamento patriarcal então existente no padrão familiar do Brasil do início do século XX (ambiente externo), sobretudo no meio rural onde o romance assenta seu cenário. Praticamente todos os papéis femininos dizem respeito a ocupantes das atividades femininas tradicionais da época, ou seja, encontramos as personagens femininas, predominantemente, exercendo atividades em torno do cuidado do lar, no interior da esfera da fazenda e da casa, dependendo da tutela masculina. Entretanto essa restrição à ação ao espaço interno é, muitas vezes, refutada, pois D. Glória, Negra Margarida e Madalena resistem a essa redução. Todavia, as investidas contra esse papel restrito nem sempre são bem sucedidas. Aos homens é reservada a posição de mando e de comando dentro 
da fazenda e fora dela. No tocante ao protagonista, ao ascender materialmente, por intermédio da posse da fazenda São Bernardo, o interesse no filho concernia apenas à formação de um herdeiro para a propriedade, alguém que pudesse levar adiante a sua linhagem, o seu sobrenome e ampliasse ou mantivesse os seus bens materiais e o seu poder político na região.

O protagonista destaca a vontade de ter um filho homem para tal fito. Entretanto, a sua empreitada não é exitosa visto que a sua propriedade e a continuidade de mando político na região se acham ameaçadas em decorrência da falência do lar que não soube ou não pode constituir. Graciliano Ramos está atento ao que ocorre no contexto externo ao romance, fazendo migrar para o interior do texto literário as condições objetivas da realidade patriarcal e autoritária externa no meio local rural, mas a partir da singularidade das vidas contadas, revela a vontade de resistência das personagens femininas como também a fraqueza e a afetividade das personagens masculinas em um meio agreste. A narrativa se insere em uma linha de resistência uma vez que apresenta a tragicidade de vidas despedaçadas em decorrência de um meio cultural opressor e materialista.

À Madalena coube o único papel biológico de mãe, dentre os personagens principais. Foi a geradora do herdeiro e deveria ser sua cuidadora. Entretanto, como se viu, Madalena não reproduziu o papel cultural que lhe era esperado, ou seja, foi incapaz de transformar o ambiente externo hostil ao filho em um ambiente favorável para o seu desenvolvimento. $\mathrm{O}$ filho fica à mercê dos cuidados de outrem, pois Madalena não se encaixa no comportamento maternal que lhe fora solicitado. Suicida-se, deixando vazio o lugar materno. O capataz, Casemiro Lopes, homem rude, simples e bruto, exercendo a atividade maternal, confirma que esta função independe de um inatismo biólogico ou de uma demanda cultural esterotipada. Aqui o romance apresenta uma situação bastante inusitada visto que a ação maternal pode ser localizada onde as regras culturais e sociais, historicamente produzidas, não tendem a ser sempre seguidas. A personagem menos propícia do ponto de vista de uma estereotipia social é a que exerce a função maternal. O meio que exige do personagem masculino que reprima sua afetividade e demonstre coragem e valentia para inclusive matar seus oponentes (Casimiro exerce também a função de jagunço na fazenda), é, em parte, neutralizado à medida que a personagem protagoniza a função maternal. A ausência da mãe biológica nos casos de Paulo Honório e Madalena não impediu que o local vazio da maternidade fosse preenchido a contento. À Negra Margarida coube o papel de mãe afetiva de Paulo Honório, aquela que o criou e lhe ensinou suas primeiras lições, já que os pais biológicos são inexistentes. Aqui Graciliano Ramos localiza na personagem negra, humilde, pobre e desprovida de linhagem 
familiar, o potencial maternal, independente de inatismo biológico ou determinantes culturais. A partir da personagem, o autor revela a possibilidade de outras formas de afetividade e sociabilidade, contando nesse sentido, uma narrativa outra em que cabe ao pequeno e ao desprovido de valor material, uma função de sustentação.

Papel similar teve Dona Glória, pois não é mãe biológica de Madalena, mas a ela devota todo o seu empenho em criá-la e educá-la. A função é, porém, intensificada pela relação familiar formal de segundo grau com Madalena. A personagem também resiste ao poder do protagonista e não se solidariza com seu filho, abandonando a fazenda, após a morte da sobrinha. A função maternal que exerce, no entanto, é pontual, restringindo-se à Madalena, demonstrando claramente que é uma construção cultural dentro de determinada situação que não se estende para o filho de Paulo Honório.

Por intermédio dessa análise das representações de certos papéis maternais no romance, percebe-se que o autor recria o contexto histórico da época, ficcionalizando o patriarcalismo e o coronelismo vigentes no meio nordestino rural, especialmente, formalizando essa realidade na figura do protagonista que exerce seu poder de mando sobre seus tutelados, homens e mulheres, mas as vidas ali contadas e narradas em sua singularidade, demonstram claramente que esse universo não se concretiza em toda a sua plenitude, pois há ações de resistência a ele, que comprometem a sua concretude. Além disso, a afetividade e a sociabilidade irrompem de lugares não previstos culturalmente para aquele meio. Há uma diretriz de que certos papéis femininos e masculinos sejam seguidos, mas são confrontados e distorcidos, formalizando uma outra narrativa em que personagens independentes de vínculos biológicos ou de determinismos culturais exerçam a maternidade, revelando que a ficção pode contar uma história que resiste ao padrão dominante.

\section{Referências}

ARIÈS, P. História social da criança e da família. 2. ed. Rio de Janeiro: LTC, 1981.

BADINTER, E. Um amor conquistado; o mito do amor materno. 2. ed. Rio de Janeiro: Nova Fronteira, 1985.

BAKHTIN, M. Questões de literatura e estética: a teoria do romance. Trad. Aurora Fornoni Bernardini et al. São Paulo: Hucitec, 1988.

CANDIDO, A. Literatura e sociedade. São Paulo: Companhia Editora Nacional, 1985. 
FAUSTO, B. A revolução de 30: historiografia e história. São Paulo: Companhia das Letras, 1997.

GOLDMAN, L. A sociologia do romance. Trad. Álvaro Cabral. 3. ed. Rio de Janeiro: Paz e Terra, 1976.

IGLESIAS, F. A industrialização brasileira. 6. ed. São Paulo: Brasiliense, 1994. (Coleção tudo é história).

NEVES, J. História geral: a construção de um mundo globalizado. 12. ed. São Paulo: Saraiva, 2002.

RAMOS, G. São Bernardo. Posfácio de Godofredo de Oliveira Neto. - 86. ed. Rio de Janeiro: Record, 2008.

SOIFER, R. Psicologia da gravidez, parto e puerpério. 6. ed. Porto Alegre: Artes Médicas, 1992.

VIANNA, L. Cenas de amor e morte na ficção brasileira: o jogo dramático da relação homem-mulher na literatura. Niterói: EDUFF, 1999.

WINNICOTT, D. W. A criança e seu mundo. Rio de Janeiro: LTC, 1982.

WINNICOTT, D. W. Conversando com os pais. São Paulo: M. Fontes, 1999.

\footnotetext{
${ }^{1}$ Utilizamos essa terminologia extraída da obra de Bakhtin (1998) para quem os aspectos de conteúdo externos à obra se formalizam em elementos composicionais do discurso, articulando texto e contexto. O teórico russo trabalha essencialmente com as estilizações dos discursos sociais que ocorrem por meio de vários expedientes técnicos no interior do discurso literário. Neste artigo usamos essa terminologia nessa acepção para averiguar como a obra "formaliza" os dados externos.

${ }^{2}$ Distancia-se totalmente de uma visão de reflexo leninista em que o texto artístico deve espelhar a realidade. $\mathrm{O}$ autor brasileiro advoga a articulação entre literatura e sociedade, mas salienta que essa interação é sempre de ordem estilística, preservando o específico do texto literário.

${ }^{3}$ Para se aprofundar no contexto patriarcal do cenário laboral, sindical, serviço público e Estado Nacional brasileiro, no período da fábula, consultar Fausto (1997) e Iglésias(1994). Esses historiadores abordam as relações entre campo e cidade e a implantação de práticas e valores liberais-burgueses no campo. Entretanto, esse novo ideário que consiste em uma visão mais empresarial e racional é também perpassado pela esfera patriarcal reinante no campo onde o poder masculino é hegemônico. Vemos Paulo Honório alterando o cenário da fazenda, modernizando-a com maquinário e tecnologias apropriadas. Há toda uma atualização tecnológica das bases materiais. O espírito empreendedor, objetivo e de racionalidade instrumental se vê na prória bibliografia que o protagonista lê para se instruir no sentido da fazenda produzir mais e melhor. Afora isso, o seu mandonismo reforça o coronelismo no campo.Esse componente é específico do local e distanciase do universo empresarial burguês, de relações mais impessoalizadas. Essas contradições entre o racionalismo e o coronelismo são típicas do meio rural descrito no romance.
} 